Sport Science: Jurnal Sain Olahraga dan Pendidikan Jasmani ISSN 114-562X (Cetak), ISSN XXXX-XXXX(Online)

http://sportscience.ppj.unp.ac.id/index.php/jss/index

\title{
Manfaat Modifikasi Permainan Kecil Dalam Proses Belajar Mengajar Pendidikan Jasmani Olahraga dan Kesehatan
}

\author{
Reza Yukaisep ${ }^{1}$, Khairuddin ${ }^{2}$, Arif Fadli Muchlis \\ ${ }^{123}$ Fakultas Ilmu Keolahragaan, Universitas Negeri Padang, Indonesia.
}

E-mail: rezayukai@noemail.com¹ ${ }^{1}, \underline{\text { khairuddin@fik.unp.ac.id }}$,

\begin{abstract}
Abstrak
Pembelajaran penjasorkes di SDN 12 Punggung Lading Kecamatan Pariaman Selatan Kota Pariaman masih ditemui banyak kasus di lapangan yang kurang tepat dan tidak diharapkan oleh siswa, antara lain: menggunakan alat dan peraturan orang dewasa. Tentu siswa akan malas dan kurang termotivasi untuk melakukan praktek dalam pembelajaran Penjasorkes. Hal ini disebabkan secara fisik dan psikis anak belum mendukung, dengan adanya modifikasi alat dan peraturan memungkinkan siswa lebih termotivasi dalam proses belajar mengajar secara baik. Sebab setiap partisipasinya mendorong untuk bekerjasama dan siswa akan merasa senang.

Tujuan dari penelitian ini adalah untuk mengetahui bagaimana persepsi siswa terhadap manfaat modifikasi permainan kecil dalam proses belajar mengajar, hal ini muncul karena selama ini siswa cenderung tidak termotivasi terhadap pelajaran Penjasorkes, sehingga siswa tidak mendapatkan kesegaran jasmani dalam mengikuti pembelajaran. Jenis penelitian ini adalah deskriptif. Waktu penelitian pada bulan Juni s/d Juli 2011.

Populasi penelitian adalah seluruh siswa SDN 12 Punggung Lading Kecamatan Pariaman Selatan Kota Pariaman kelas IV dan kelas V yang berjumlah 24 orang, terdiri dari 11 orang putra, dan 13 orang putri. Penarikan sampel dilakukan dengan teknik total sampling, yaitu dengan mengambil secara keseluruhan dari populasi, jadi sampel berjumlah 24 orang. Instrumen yang dipakai untuk mengumpulkan data adalah Angket atau kuesioner dengan menggunakan skala Guttmant. Data dianalisis dengan menggunakan rumus distribusi frekuensi dalam bentuk persentase.

Dari analisis data diperoleh hasil penelitian sebagai berikut: variabel peranan permainan kecil terhadap pembelajaran dari 29 pertanyaan yang diajukan tingkat capaian responden mencapai $68,10 \%$. Dari temuan tersebut dapat diambil kesimpulan bahwa tingkat capaian peranan manfaat modifikasi permainan kecil dalam proses belajar mengajar pembelajaran pendidikan jasmani, olahraga dan kesehatan di SDN 12 Punggung Lading Kecamatan Pariaman Selatan Kota Pariaman dikategorikan cukup.
\end{abstract}

Kata Kunci: Mofidikasi Permainan, Proses Belajar Mengajar, Pendidikan Jasmani dan Olahraga

\begin{abstract}
Physical education learning at SDN 12 Punggung Lading, South Pariaman Subdistrict, Kota Pariaman still encountered many cases in the field that were not appropriate and were not expected by students, including: using adult tools and regulations. Of course students will be lazy and less motivated to practice in learning Physical Education. This is caused physically and psychologically the child has not been supportive, with the modification of tools and regulations allowing students to be more motivated in the process of teaching and learning well. Because every participation encourages cooperation and students will feel happy.

The purpose of this study is to find out how students' perceptions of the benefits of modifying small games in the teaching and learning process, this arises because so far students tend not to be motivated towards Penjasorkes lessons, so students do not get physical fitness in following learning. This type of research is descriptive. The time of the study was in June to July 2011.
\end{abstract}


The study population was all students of SDN 12 Punggung Lading, South Pariaman Subdistrict, Pariaman City, class IV and class V, totaling 24 people, consisting of 11 sons and 13 daughters. Sampling is done by total sampling technique, which is by taking as a whole from the population, so the sample is 24 people. The instrument used to collect data was a questionnaire or questionnaire using the Guttmant scale. Data were analyzed using the formula of frequency distribution in the form of a percentage.

From the data analysis, the results of the study are as follows: the role of small play variables towards learning from 29 questions raised by respondents reached 68.10\%. From these findings it can be concluded that the level of achievement of the role of the benefits of modifying small games in the teaching and learning process of physical education, sports and health in SDN 12 Punggung Lading, South Pariaman Subdistrict, Pariaman City is categorized as sufficient.

Keywords Game Mofidication, Teaching and Learning Process, Physical Education and Sports

\section{PENDAHULUAN}

Penerapan metode yang sistematis merupakan faktor yang dapat menjawab tantangan pembelajaran Penjasorkes. Untuk itu yang perlu dilakukan terhadap anak didik adalah bagaimana menciptakan suasana belajar yang bergairah, menarik sehingga siswa senang dan tidak jenuh dalam mengikuti pelajaran penjas. Untuk dapat menghasilkan hal tersebut maka perlu adanya metode pembelajaran yang tepat. Menurut Asnaldi (2018:26) ;

"Hasil belajar penjasorkes tidak hanya dipengaruhi oleh variabel motivasi olahraga dan kemampuan motorik saja, melainkan banyak variabel lain yang dapat mempengaruhi hasil belajar penjasorkes siswa. Diantaranya sarana dan prasarana pembelajaran, kemampuan guru dalam mengajar dan pemilihan metode dan media yang tepat untuk suatu materi pembelajaran, status gizi dan kesegaran jasmani siswa juga dapat mempengaruhi kesiapan siswa dalam belajar, begitu juga dengan lingkungan belajar".

Salah satu metode pembelajaran yang perlu dan dibutuhkan dalam pelajaran penjasorkes adalah membuat modifikasi. Dengan membuat model memodifikasi pembelajaran yang tepat dan sifatnya spesifikasi dan menarik tentunya akan dapat menarik minat siswa untuk mengikuti kegiatan pembelajaran penjasorkes.

Berdasarkan hasil pengamatan sementara yang dilakukan di SDN 12 Punggung Lading Kecamatan Pariaman Selatan Kota Pariaman pembelajaran penjasorkes ditemui masih banyak kasus di lapangan yang kurang tepat dan tidak diharapkan oleh siswa, antara lain: menggunakan alat dan peraturan orang dewasa. Tentu siswa akan malas dan kurang termotivasi untuk melakukan praktek dalam pembelajaran Penjasorkes.

Hal ini disebabkan secara fisik dan psikis anak belum mendukung, dengan adanya modifikasi alat dan peraturan memungkinkan siswa lebih termotivasi dalam proses belajar mengajar secara baik. Sebab setiap partisipasinya mendorong untuk bekerjasama dan siswa akan merasa senang karena pendidikana tidak saja mengajarkan bagaimana siswa melakkan atau menindak lanjuti intruksi yang diberikan oleh guru. Menurut Redawati, dkk (2017:12) yaitu Pendidikan lebih menitikberatkan pada pembentukan dan pengembangan kepribadian, jadi mengandung pengertian yang lebih luas, sedangkan latihan (training) lebih menekankan pada pembentukan (skill).

Untuk itu, guru penjasorkes perlu menciptakan variasi tugas yang menarik perhatian siswa. Disamping itu peran orangtua dirumah sebagai agen sosialisai perilaku motorik anak perlu memperhatikan kegiatan bermaian anaknya yang dapat memberikan sumbangan pada kesegaran jasmani. Kiram (1992) menyatakan modifikasi olahraga kedalam penjasorkes ada empat unsur yang perlu diperhatikan oleh guru, yaitu : (a) modifikasi ukuran lapangan ; (b) modifikasi peralatan ; (c) modifikasi lamanya permainan ; (d) Modifikasi peraturan permainan 
Modifikasi ukuran lapangan dan waktu main bertujuan untuk mengurangi tuntutan kemampuan fisik siswa. Dalam beberapa kasus seperti berikut : Siswa Sekolah Dasar bermain bolavoli pada lapangan yang berukuran standar dengan menggunakan tinggi net dan bola ukuran orang dewasa, tentu semua ini mempersulit siswa untuk membuat skor atau sama sekali siswa tidak mampu untuk menyeberangkan bola lewat net. Modifikasi ukuran lapangan dapat disesuaikan dengan situasi dan kondisi lapangan yang tersedia disekolah.

Modifikasi lamanya permainan bertujuan untuk memberikan konsentrasi yang penuh dan kesenangan bagi siswa dalam melakukan penjasorkes. Waktu yang lama akan membosankan siswa dalam melakukan tugas gerakan. Untuk itu guru harus merencanakan secara matang tentang penggunaan waktu yang tetap mengacu pada pola pengajaran. Dalam hal ini adanya semacam fleksibilitas dan penggunaan waktu yang ada. Modifikasi peraturan permainan bermaksud membantu siswa mengembangkan keterampilan dan kesenangan dalam melakukan penjasorkes tanpa merusak keaslian dari permainan tersebut. Peraturan yang dibuat dalam permainan yang dilakukan disepakati secara bersama atau guru yang menetapkannya terlebih dahulu dan selanjutnya diberitahukan kepada siswa. Unsur kebersamaan dan disiplin terhadap apa yang sudah disepakati sangat diperlukan.

\section{METODE}

Jenis penelitian yang dilakukan adalah deskriptif yang bertujuan untuk meninjau dan mendeskripsikan suatu keadaan pada saat penelitian dilakukan. Penelitian dilakukan pada bulan Juni s/d Juli 2011. Adapun penelitian ini diadakan di SDN 12 Punggung Lading Kecamatan Pariaman Selatan Kota Pariaman. Populasi dalam penelitian ini adalah siswa yang duduk dikelas V, alasannya karena pembelajaran penjas berdasarkan KTSP baru diberikan pada siswa kelas IV dan siswa V, sementara kelas VI sudah mengikuti ujian akhir/UAS sehingga tidak bisa diikutsertakan sebagai populasi dalam penelitian ini. Adapun jumlah populasi kelas V yaitu 24 orang siswa.

\section{Tabel 1}

Populasi Penelitian

\begin{tabular}{ccccc}
\hline No & SDN 12 Punggung & \multicolumn{2}{c}{ Jumlah Siswa } & Jumlah \\
& Lading & Laki-laki & Perempuan & Populasi \\
\hline 1 & Kelas IV & 5 & 7 & 12 \\
2 & Kelas V & 6 & 6 & 12 \\
& Jumlah & 11 & 13 & 24 \\
\hline
\end{tabular}

Sumber : Data SDN 12 Punggung Lading Kecamatan Pariaman Selatan Kota Pariaman

Jika populasi kurang dari 100 lebih baik semua populasinya dijadikan sampel, selanjutnya jika populasinya lebih dari 100 maka sampelnya minimal 10-25\%. Berdasarkan pendapat Hadi diatas maka jumlah siswa yang dijadikan sampel dalam penelitian ini yaitu $100 \%$ dari jumlah populasi yang ada atau 24 orang siswa. Teknik pengambilan sampel adalah secara Total Sampling. Untuk lebih jelasnya perhatikan tabel berikut :

Tabel 2

Sampel Penelitian

\begin{tabular}{ccccc}
\hline \multirow{2}{*}{ No } & SDN 12 Punggung & \multicolumn{2}{c}{ Jumlah Siswa } & Jumlah \\
& Lading & Laki-laki & Perempuan & $\begin{array}{c}\text { Populasi } \\
\text { 1 }\end{array}$ \\
Kelas IV & 5 & 7 & 12 \\
2 & Kelas V & 6 & 6 & 12 \\
& Jumlah & 11 & 13 & 24 \\
\hline
\end{tabular}

Variabel independent adalah bentuk manfaat modifikasi dan variabel independent adalah mata pelajaran penjasorkes, terdapat dua jenis data yang akan diambil pada penelitian ini yaitu:

a. Data primer yaitu data tentang model modifikasi. Data ini diperoleh melalui sebuah kuesioner ( penyebaran angket ) 
b. Data sekunder yaitu data dan pembelajaran penjasorkes di SDN 12 Punggung Lading Kecamatan Pariaman Selatan Kota Pariaman yang diperoleh dari nilai rapor siswa.

\section{Instrumen Penelitian}

Alat yang digunakan untuk mengumpulkan data pada penelitian ini yaitu kuesioner 9 (angket). Kuesioner ini di gunakan untuk memperoleh data tentang model modifikasi. Kuesioner ini diisi oleh siswa yang terpilih menjadi responden dan bertujuan untuk mendapatkan data atau informasi sehubungan dengan model modifikasi dalam mata pelajaran penjasorkes di SDN 12 Punggung Lading Kecamatan Pariaman Selatan Kota Pariaman.

1. Menentukan Indikator Variabel

Menurut Arikunto ( 1989:169), yang dimasud dengan indicator adalah "sesuatu yang dapat menunjukkan atau menjadi petunjuk bagi sub-variabel atau variabel". Bertitik tolak dari kajian teori yang diuraikan diatas maka dalam penelitian ini ada 2 variabel bebas yaitu : (1) Model modifikasi permainan bola voli dengan indikator modifikasi jumlah permainan, tinggi net, ukuran lapangan, ukuran bola, peraturan permainan, (2) model modifikasi atletik lari jarak pendek dengan indicator modifikasi lintasan jarak dan cara start.

2. Penyusunan Instrumen

Pengumpulan data dengan angket yaitu suatu cara pengumpulan data dengan menyusun daftar pertanyaan yang diberikan kepada orang lain untuk bersedia memberikan respon sesuai permintaan. Ridwan (2003:12) menjelaskan bahwa angket sebagai alat utama mengumpulkan data disusun dengan menggunakan skala sikap (qutmen) dalam penyusunan angket dilakukan beberapa tahap: yaitu penentuan indicator, kisi-kisi dan angket. Setiap butir pertanyaan disediakan 2 pilihan jawaban yaitu a ( ya ) dan b ( tidak ). Dimana responden yang menjawab ya pada item diberi skor 1 dan sebaliknya responden yang memberikan jawaban tidak diberikan skor 0 .

\section{Analisis Data}

Analisis data yang digunakan yaitu dengan menggunakan analisis deskripsi yang menyajikan data tentang tingkat pencapaian responden masing-masing variabel penelitian, seperti : skor rata-rata ( mean ), median, modus, standar deviasi, tabel distribusi frekwensi, dan tingkat pencapaian responden masing-masing variabel penelitian dengan menggunakan analisis skor ideal. Untuk mengetahui tingkat capaian masing-masing kategori jawaban untuk setiap variabel dan indikator maka dengan digunakan nilai skor rata-rata. Adapun langkah dalam analisis data ini yaitu :

1 Mentabulasi jawaban responden pada tabel persiapan sesuai dengan indikator masing-masing variabel

2 Menghitung frekuensi jawaban

3 Menghitung skor rata-rata dengan memberi bobot formatif data alternatif jawaban sesuai dengan skala Guttmant. Sesudah itu baru dicari jumlah skor masing-masing butir dengan jalan mengkalikan frekuensi dengan bobot masing-masing . kemudian dicari skor rata-rata masingmasing butir untuk setiap sub variabel guna mendapatkan gambaran dari setiap sub variabel.

Untuk menentukan gambaran secara kuantitatif hasil penelitian untuk masing-masing sub variabel penelitian, menggunakan kriteria skor nilai ideal adalah sebagai berikut (Sudjana , 1982):

$$
\text { skor nilai ideal } \quad=\frac{\text { skor rata-rata }}{\text { skor maksimal ideal }} \quad \text { x 100\% }
$$

Klasifikasi nilai yang dicapai oleh responden menggunakan klasifikasi menurut Sudjana (1982) dengan pengkategorian sebagai berikut :

$\begin{array}{llll}90 \% & - & 100 \% & \text { sangat baik } \\ 80 \% & - & 89 \% & \text { baik }\end{array}$




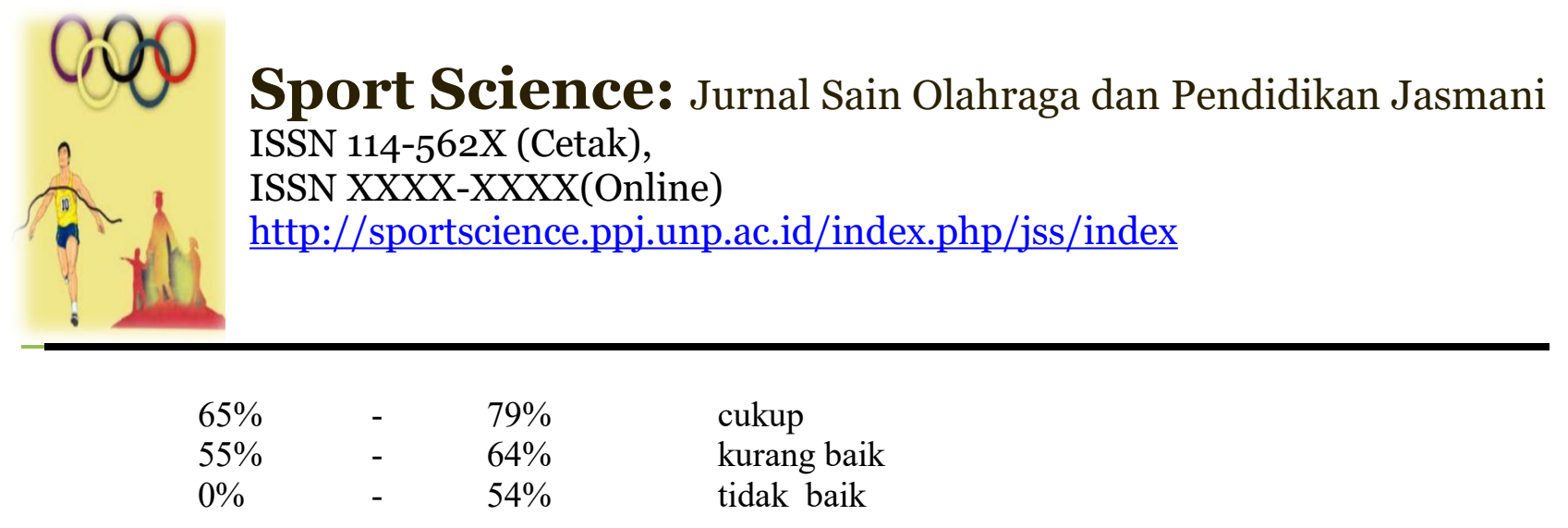

\section{HASIL DAN PEMBAHASAN \\ Hasil Penelitian}

Pada Bab ini dikemukakan deskripsi data dan pembahasan hasil penelitian sesuai dengan pertanyaan penelitian yang diajukan. Sebelum dilakukan analisis terhadap data "Manfaat modifikasi permainan kecil dalam proses belajar mengajar (PBM) pendidikan jasmani olahraga dan kesehatan bagi siswa SDN 12 Punggung Lading Kecamatan Pariaman Selatan Kota Pariaman" yang ditinjau dari aspek persepsi siswa, maka dilakukan verifikasi (seleksi) terhadap data yang telah diperoleh.

Tujuan dilakukan verifikasi data adalah apabila ada data yang tidak lengkap yang diisi oleh responden dalam instrumen, maka data tersebut tidak dapat diolah. Kriteria lengkapnya data yang diisi responden terhadap instrumen apabila seluruh pertanyaan dijawab sesuai dengan instruksi yang ada dalam instrumen tersebut. Berdasarkan hasil verifikasi terhadap data yang diperoleh, ternyata semua data dapat diolah.

Deskripsi data yang dilakukan dalam penelitian ini adalah untuk melihat karakteristik distribusi data dari variabel pertanyaan yang meliputi aspek tentang manfaat modifikasi permainan kecil dalam proses belajar mengajar (PBM) pendidikan jasmani olahraga dan kesehatan bagi siswa SDN 12 Punggung Lading Kecamatan Pariaman Selatan Kota Pariaman. Untuk melihat Manfaat modifikasi permainan kecil dalam proses belajar mengajar (PBM) pendidikan jasmani olahraga dan kesehatan bagi siswa SDN 12 Punggung Lading Kecamatan Pariaman Selatan Kota Pariaman, peneliti memberikan 29 butir pertanyaan.

Dari hasil penelitian pada tabel 3 distribusi frekuensi di atas terlihat bahwa dari 29 pertanyaan, skor tertinggi adalah pada butir pertanyaan nomor 14 yang menanyakan bahwasanya siswa dalam pelaksanaan proses pelajaran praktek Penjasorkes begitu bergairah dengan melakukan setiap kegiatan yang diberikan terutama jika dikreasikan dengan modifikasi dalam pembelajaran siswa akan merasa lebih senang, ini terbukti dengan jawaban responden yang mencapai skor 24 dan dengan tingkat capaian $100 \%$.

Pada butir pertanyaan nomor 22 yang membahas tentang siswa akan merasa bebas beraktivitas terhadap modifikasi dalam pembelajaran dan juga siswa akan gembira apabila suasana yang ada disekitarnya mendukung terhadap kegiatan yang dilakukan, ini terbukti dengan jawaban responden yang mencapai skor 24 dan dengan tingkat capaian $100 \%$, ini berarti bahwa manfaat modifikasi permainan kecil dalam proses belajar mengajar (PBM) pendidikan jasmani olahraga dan kesehatan bagi siswa SDN 12 Punggung Lading Kecamatan Pariaman Selatan Kota Pariaman berjalan dengan sangat baik.

Sedangkan skor terendah terdapat pada butir pertanyaan nomor 21 yaitu "letak sekolah sangat mempengaruhi konsentrasi saya dalam melakukan pelajaran praktek Penjasorkes", dengan skor 3 responden dan tingkat capaian $12,50 \%$. Ini artinya manfaat modifikasi permainan kecil dalam proses belajar mengajar (PBM) pendidikan jasmani olahraga dan kesehatan bagi siswa SDN 12 Punggung Lading Kecamatan Pariaman Selatan Kota Pariaman tetap berlangsung dengan baik meskipun letak sekolah tidak kondusif, hal ini dikategorikan kurang sekali. Artinya PBM Penjasorkes tidak berpengaruh besar terhadap keadaan sekolah terutama jika dipadukan dengan permainan kecil dalam PBM Penjasorkes dilapangan.

Tabel 4

Deskripsi Manfaat Modifikasi Permainan Kecil Pembelajaran Penjasorkes bagi siswa SDN 12 Punggung Lading Kecamatan Pariaman Selatan Kota Pariaman 


\begin{tabular}{ccccc}
\hline No & $\begin{array}{c}\text { Kategori } \\
\text { Jawaban }\end{array}$ & $\begin{array}{c}\text { Jawaban } \\
\text { Responden }\end{array}$ & $\begin{array}{c}\text { Persentase } \\
(\%)\end{array}$ & $\begin{array}{c}\text { Tingkat } \\
\text { Capaian }\end{array}$ \\
\hline 1 & Ya & 474 & 68,10 & \\
2 & Tidak & 222 & 31,90 & $\mathbf{6 8 , 1 0 \%}$ \\
& Jumlah & $\mathbf{6 9 6}$ & $\mathbf{1 0 0}$ & \\
\hline
\end{tabular}

Pada Tabel 4 di atas dapat diketahui bahwa dari 24 orang responden dan dari 29 butir pertanyaan, yang memilih jawaban "Ya" sebanyak 474 responden atau 68,10\%. Dan yang menjawab "Tidak" adalah 222 responden atau 31,90\%.

Secara keseluruhan tingkat capaian manfaat modifikasi permainan kecil dalam proses belajar mengajar (PBM) pendidikan jasmani olahraga dan kesehatan bagi siswa SDN 12 Punggung Lading Kecamatan Pariaman Selatan Kota Pariaman yang diperoleh dari 24orang responden untuk 29 butir pertanyaan adalah sebesar $68,10 \%$, itu artinya bahwa tingkat capaian manfaat modifikasi permainan kecil dalam proses belajar mengajar (PBM) pendidikan jasmani olahraga dan kesehatan bagi siswa SDN 12 Punggung Lading Kecamatan Pariaman Selatan Kota Pariaman berada pada klasifikasi cukup. Gambaran lebih jelasnya dapat dilihat pada grafik histogram berikut ini:

Gambar 4

Histogram Manfaat Modifikasi Permainan Kecil Pembelajaran Penjasorkes bagi siswa SDN 12 Punggung Lading Kecamatan Pariaman Selatan Kota Pariaman

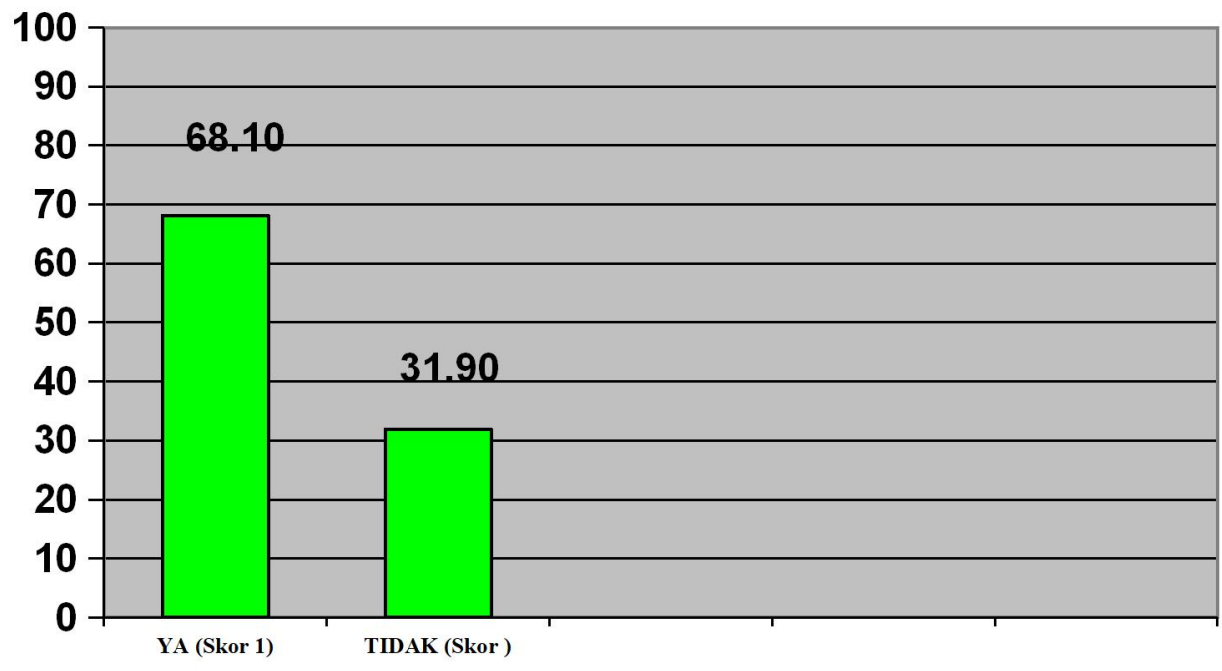

\section{Pembahasan}

Berdasarkan hasil penelitian yang telah diuraikan di atas, variabel manfaat modifikasi permainan kecil pembelajaran Penjasorkes bagi siswa SDN 12 Punggung Lading Kecamatan Pariaman Selatan Kota Pariaman. selanjutnya dapat dilihat pada pembahasan selanjutnya.Pada tabel 3 dapat dilihat secara keseluruhan tingkat capaian manfaat modifikasi permainan kecil pembelajaran Penjasorkes bagi siswa SDN 12 Punggung Lading Kecamatan Pariaman Selatan Kota Pariaman yang diperoleh sebesar $68,10 \%$. Artinya bahwa tingkat capaian manfaat modifikasi permainan kecil pembelajaran Penjasorkes bagi siswa SDN 12 Punggung Lading Kecamatan Pariaman Selatan Kota Pariaman cukup. Menurut Sudjana (1982) bahwa klasifikasi tingkat capaian antara 65-79 berada pada kategori cukup. Dengan demikian dapat disimpulkan bahwa manfaat modifikasi permainan kecil pembelajaran Penjasorkes bagi siswa SDN 12 Punggung Lading Kecamatan Pariaman Selatan Kota Pariaman sudah berjalan dengan kategori cukup, namun perlu dilakukan usaha-usaha yang mengarah kepada peningkatan agar manfaat modifikasi permainan kecil akan terlaksana dengan baik. 
Sport Science: Jurnal Sain Olahraga dan Pendidikan Jasmani ISSN 114-562X (Cetak), ISSN XXXX-XXXX(Online)

http://sportscience.ppj.unp.ac.id/index.php/jss/index

Manfaat modifikasi sebenarnya cukup signifikan terhadap usaha meningkatkan kesegaran jasmani anak-anak, biasanya anak-anak cenderung akan termotivasi dalam melakukan segala bentuk aktifitas fisik yang dikreasikan dengan permainan kecil apabila Guru mampu mengemasnya dengan baik. Hal ini sejalan dengan Mutohir (2002) yang menyatakan bahwa: "modifikasi olahraga dapat memotivasi anak untuk berpartisipasi dan senang bergerak. Dampak dari modifikasi lapangan, alat-alat yang digunakan serta aturan yang ada tentu akan memberikan kesempatan kepada siswa untuk dapat bergerak dan berkreasi dalam melakukan Penjasorkes".

\section{KESIMPULAN}

Berdasarkan hasil penelitian tentang persepsi Guru Penjas terhadap modifikasi dalam pembelajaran Penjasorkes pada SDN 12 Punggung Lading Kecamatan Pariaman Selatan Kota Pariaman, maka dapat ditarik kesimpulan: Tingkat capaian manfaat modifikasi permainan kecil dalam proses belajar mengajar (PBM) pendidikan jasmani olahraga dan kesehatan bagi siswa SDN 12 Punggung Lading Kecamatan Pariaman Selatan Kota Pariaman berada pada tingkat capaian sebesar $68,10 \%$.nTingkat capaian manfaat modifikasi permainan kecil dalam proses belajar mengajar (PBM) pendidikan jasmani olahraga dan kesehatan bagi siswa SDN 12 Punggung Lading Kecamatan Pariaman Selatan Kota Pariaman berada pada klasifikasi cukup.

selanjutnya peneliti mengemukakan beberapa saran yaitu kepada : Guru pembimbing yang ada SDN 12 Punggung Lading Kecamatan Pariaman Selatan Kota Pariaman dalam rangka meningkatkan kreatifitas dan kesegaran jasmani siswa, dapat menambah ilmu pengetahuan tentang modifikasi pembelajaran Penjasorkes dan juga mengikuti penataran-penataran, seminar-seminar khususnya yang berkenaan dengan pengembangan keterampilan mengajar.

Kepala Sekolah yang ada di SDN 12 Punggung Lading Kecamatan Pariaman Selatan Kota Pariaman dalam rangka meningkatkan kualitas pembelajaran dan hasil yang diharapkan, agar dapat memberikan dukungan, baik itu dukungan moril maupun materil. Siswa SDN 12 Punggung Lading Kecamatan Pariaman Selatan Kota Pariaman yang mengikuti pelajaran Penjasorkes agar lebih bersemangat belajar agar mencapai hasil belajar dan kesegaran jasmani yang lebih baik. Orangtua dan masyarakat dalam rangka meningkatkan kualitas pembelajaran dan hasil yang diharapkan, agar dapat memberikan dukungan kepada sekolah, baik itu dukungan moril maupun materil.

\section{DAFTAR RUJUKAN}

Arikunto, Suharsimi (1989). Manajemen Penelitian. Jakarta: P2LPTK.

Asnaldi, A., FIK-UNP, Z., \& M, M. (2018). Hubungan Motivasi Olahraga Dan Kemampuan Motorik Dengan Hasil Belajar Pendidikan Jasmani Olahraga Dan Kesehatan Siswa Sekolah Dasar Negeri 16 Sintoga Kecamatan Sintuk Toboh Gadang Kabupaten Padang Pariaman. Jurnal MensSana, 3(2), 16-27. doi:10.24036/jm.v3i2.75

Depdikbud (1993). Kebijakan Pemerintah Dalam Pembinaan Sekolah Dasar.

Gagne dan Briggs (1960). Nutrition and Physical Fitness. Philadephia

Hadi .(1993). Metode Penelitian. Jakarta Balai Pustaka

Jones, Don. (1995). Bahan Penataran Modifikasi Olahraga kedalam Pendidikan Jasmani, tanggal 514 Juni. Surabaya. FPOK IKIP Surabaya. 
Kiram, Yanuar (1992). Belajar Motorik. Jakarta Departemen Pendidikan dan Kebudayaan

Lutan, Rusli .(1998). Belajar Keterampilan Motorik. Pengantar teori dan metode. Jakarta. Departemen Pendidikan dan Kebudayaan.

Mutohir, T. Cholik (2002). The Futurof Physical Education in Indonesia. paper presented in the workshop-seminar on modification to sport with in physical education: an alternative strategy to teaching. Australian Indonesia sport program, 5-14 juni 1995. FPOK IKIP Surabaya.

Mutohir, T. Cholik dan Gusril (2008). Perkembangan Motorik Pada Masa Kanak-kanak. Padang. Direktorat Jenderal Olahraga Departemen Pendidikan Nasional.

Redawati, R., Asnaldi, A., \& Mardela, R. (2017). Persepsi Guru-Guru Non Penjas terhadap Pembelajaran Pendidikan Jasmani Olahraga Kesehatan dan Rekreasi Gugus IV Sungai Jambu Kecamatan Pariangan. Sport Science, 17(1), 10-18. https://doi.org/10.24036/jss.v17i1.1

Sudjana (1992). Metode Statistika ( Edisi Ke-5 ). Bandung: Tarsito.

Suharta. (2002). Pedoman Pembinaan Kesegaran Jasmani . Jakarta. Dikbud.

Suparmo. (2000). Pengembangan Kurikulum Pendidikan Jasmani. Jakarta. UNJ. 